\title{
Case report of atypical hemolytic uremic syndrome with retinal arterial and venous occlusion treated with eculizumab
}

This article was published in the following Dove Press journal:

International Medical Case Reports Journal

13 October 2015

Number of times this article has been viewed

\section{Gregory T Greenwood}

Nephrology Associates, PLLC, Winston-Salem, NC, USA
Correspondence: Gregory T Greenwood Nephrology Associates, PLLC,

730 Highland Oaks Drive, Suite 20I, Winston-Salem, NC 27I03, USA

Tel +I 3367682425

Fax + I 3367684915

Email gtgreen@wakehealth.edu

\begin{abstract}
Atypical hemolytic uremic syndrome (aHUS) is a rare disease caused by chronic, uncontrolled activation of the alternative complement pathway, leading to thrombotic microangiopathy. Renal impairment and progression to end-stage renal disease are common in untreated patients with aHUS, and extrarenal manifestations are being increasingly characterized in the literature. Ocular involvement remains rare in aHUS. This report describes a patient with aHUS with bilateral central retinal artery and vein occlusion, vitreous hemorrhage, and blindness in addition to renal impairment. The patient's hematologic and renal parameters and ocular manifestation improved following initiation of eculizumab therapy.
\end{abstract}

Keywords: acute kidney injury, complement, dialysis, plasma exchange, thrombotic microangiopathy

\section{Introduction}

Atypical hemolytic uremic syndrome (aHUS) is a rare, genetic, progressive disease caused by chronic, uncontrolled alternative complement activation that leads to potentially life-threatening thrombotic microangiopathy (TMA).${ }^{1-3}$ aHUS frequently presents abruptly with microangiopathic hemolytic anemia, thrombocytopenia, and acute renal failure, and up to $79 \%$ of patients have permanent renal damage, require dialysis, or die within 3 years of onset. ${ }^{4}$ Extrarenal TMA events are increasingly characterized as occurring in up to half of all patients, ${ }^{5}$ although ocular involvement has only been described in rare cases of diagnosed aHUS. ${ }^{6-10}$ To my knowledge, only two such cases involving bilateral serous retinal detachment ${ }^{9}$ and bilateral retinal vein occlusion/venous stasis retinopathy ${ }^{10}$ have been reported since the approval of eculizumab, a terminal complement inhibitor, in 2011 for treatment of aHUS. ${ }^{11,12}$ Herein, a case of aHUS with bilateral central retinal artery and vein occlusion, vitreous hemorrhage, and blindness that improved following eculizumab therapy is described. The review board at our practice does not require approval or patient consent for publication of case reports.

\section{Case report}

The patient was a 26-year-old African American woman with recent history of hospitalization for possible rheumatic fever with pyrexia, polyserositis, cardiac tamponade requiring pericardial drainage, and pericarditis. She presented on July 19, 2013, following 3 days of progressive abdominal pain, nausea, vomiting, and diarrhea. The patient had recently quit smoking and had family history of mild hypertension but not stroke or clotting disorders. At the time of presentation, the patient was being treated with colchicine $0.6 \mathrm{mg}$, lisinopril $20 \mathrm{mg}$, omeprazole $20 \mathrm{mg}$, pantoprazole $40 \mathrm{mg}$, 
ranitidine $150 \mathrm{mg}$, and tramadol $50 \mathrm{mg}$ daily; penicillin $\mathrm{G} 2.5$ million units; and albuterol for shortness of breath. Physical findings included tachycardia (112 beats per minute) with $2 / 6$ systolic murmur. Abnormal laboratory levels included severe leukocytosis $\left(41 \times 10^{9} / \mathrm{L}\right.$; normal range: $\left.4.5-11.0 \times 10^{9} / \mathrm{L}\right)$, hemoglobin (107 g/L; normal range: 140-175 g/L), and serum albumin (28 g/L; normal range: 35-50 g/L). The patient's serum creatinine level was $53 \mu \mathrm{mol} / \mathrm{L}$ (normal range: $53-106 \mu \mathrm{mol} / \mathrm{L}$ ). Urinalysis revealed $1+$ protein. The patient complained of severe abdominal and pelvic pain; computed tomography was notable for colitis and stable mild ascites. Sepsis, possibly related to Clostridium difficile colitis, was presumed. She was placed on intravenous metronidazole and fluids, as well as oral vancomycin, and was admitted to the transitional intensive care unit.

The patient received a nephrology consultation 4 days later for potential oliguric acute tubular necrosis, and possibly vasculitis, in the setting of sepsis. Her serum creatinine level increased from 53 to $159 \mu \mathrm{mol} / \mathrm{L}$. Her leukocyte count increased to $60 \times 10^{9} / \mathrm{L}$ and platelet count decreased from $235 \times 10^{9} / \mathrm{L}$ to $71 \times 10^{9} / \mathrm{L}$ (normal range: $150-350 \times 10^{9} / \mathrm{L}$ ) with a stable hemoglobin level. The patient was prepped for investigations for vasculitis, including percutaneous renal biopsy. However, upon further evaluation, it was discovered that the patient had new-onset anemia and clear hemolytic anemia with schistocytes present on peripheral smear. Her lactate dehydrogenase (LDH) level was elevated $(3.69 \mu \mathrm{kat} / \mathrm{L}$ [221 U/L]; normal range: $1.7-3.4 \mu \mathrm{kat} / \mathrm{L}$ ) and a diagnosis of thrombotic thrombocytopenic purpura (TTP) was presumed. The patient initiated high-dose steroids and daily plasma exchange (PE). An ADAMTS13 (a disintegrin and metalloproteinase with a thrombospondin type 1 motif, member 13) level was drawn 3 days following initiation of PE and, thus, was inconclusive.

After 13 days, the patient was transferred, continued to receive daily $\mathrm{PE}$, and dialysis and mycophenolate mofetil were initiated. She developed a seizure disorder, for which levetiracetam was initiated. After reporting vision loss during which she was only able to see light and faint color, significant bilateral retinal damage including disc, macular, and retinal hemorrhages in all four quadrants to the mid-periphery was identified and presumed irreversible. Interventions including vitrectomy and injection of vascular endothelial growth factor inhibitors were considered but not performed. The patient was discharged to receive dialysis and PE three times weekly in an outpatient setting and continued follow-up with a retinal specialist for bilateral central artery and vein occlusion, vitreous hemorrhage, and blindness with a bestnoted acuity of 1-2 feet.

By September 2, 2013, the patient received PE every other day and dialysis three times weekly with no improvement. Her ADAMTS13 activity level was determined to be $61 \%$. A diagnosis of aHUS was considered and eculizumab was initiated on September 11, 2013. Shortly afterward, her renal indices began to improve: she had little interdialytic weight gain and increased urinary output. Hemodialysis and PE were discontinued in October 2013. The patient presented to the emergency department with a hypertensive emergency and altered mental status on October 27, 2014, indicating a potential TMA complication; subsequently, the eculizumab dosing schedule was shortened from 14 to 12 days.

On June 30, 2014 (last follow-up), the retinal specialist noted that her eyes were clearing and did not plan any additional therapies. The patient acknowledged improvement in sight and functional status, and walked without assistance. She continues to receive eculizumab 1,200 mg every 12 days. Her most recent laboratory tests on July 2, 2014, included a platelet count of $527 \times 10^{9} / \mathrm{L}$, normal hemoglobin and LDH levels, and a serum creatinine level of $139 \mu \mathrm{mol} / \mathrm{L}$.

\section{Discussion}

As far as I am aware, this is one of the first cases of aHUS associated with bilateral retinal vascular occlusion, and one of the first with renal and ocular involvement to be treated with eculizumab. Supportive care with PE was not effective in this patient, and led to the development of bilateral ocular TMA. Improvement in renal function and resolution of the ocular occlusions and vitreous hemorrhage occurred following initiation of eculizumab therapy, which has been shown to inhibit complement-mediated TMA and be well tolerated in patients with aHUS in four prospective clinical trials. ${ }^{13-16}$ Importantly, administration of eculizumab also led to discontinuation of $\mathrm{PE}$ and dialysis, as well as patientreported improvement in overall functional status, in the current case.

It is worth noting that the patient in this case had positive outcomes with eculizumab despite a delay in diagnosis. TTP was initially presumed and then aHUS was considered when ADAMTS13 testing results became available and the patient's renal function and ocular manifestation did not improve with PE. Diagnosis of aHUS, and particularly differential diagnosis with TTP, can be complex in adults. ${ }^{17}$ Recent guidelines for the diagnosis and treatment of aHUS state that certain laboratory values at the time of TMA are 
highly suggestive of aHUS compared with $\mathrm{TTP},{ }^{17}$ including serum creatinine levels $>200 \mu \mathrm{mol} / \mathrm{L}$ and platelet counts $>30 \times 10^{9} / \mathrm{L} .{ }^{18}$ These findings allow clinicians to anticipate the outcome of ADAMTS13-activity testing. ${ }^{19}$ Recent recommendations include initiation of eculizumab therapy in all patients in whom an aHUS diagnosis is suspected. ${ }^{5}$ Testing for complement gene abnormalities is not required for diagnosis, ${ }^{5}$ and was not performed for this patient. Levels of complement components were tested throughout the course of this patient's follow-up and were always normal, which is consistent with findings from a large case series of patients with aHUS. ${ }^{4}$

Dysregulation of the alternative pathway of complement has been previously implicated in retinal pathophysiology. For example, variants in the gene encoding complement factor $\mathrm{H}$ have been associated with the development of age-related macular degeneration. ${ }^{20}$ The $Y 402 H$ haplotype has been shown to confer particular risk, ${ }^{21}$ and analyses of protein structure and function support a causal link between the polymorphism and development of this ocular disease. ${ }^{22}$ Because the patient in the current case has not undergone genetic testing, it is not possible to speculate whether polymorphisms/ mutations in the gene encoding complement factor $\mathrm{H}$ may have contributed to this patient's retinal pathogenesis.

There are rare reports of ocular manifestations of aHUS from the pre-eculizumab era. ${ }^{6-8}$ More recent publications have chronicled the development and resolution of ocular manifestations in aHUS patients since the availability of eculizumab. ${ }^{9,10}$ A case study of a patient with preeclampsia and HELLP (hemolysis, elevated liver enzymes, and low platelet count) syndrome who developed thrombocytopenia, elevated liver enzymes, and progressive renal failure demonstrated bilateral retinal serous detachment following diagnosis of aHUS and initiation of PE, dialysis, and steroids. ${ }^{9}$ Following initiation of eculizumab therapy, the hematologic, renal, and ocular components of her TMA manifestation resolved. Most recently, the first case of recurrent ocular involvement in pediatric aHUS was reported. ${ }^{10} \mathrm{An}$ 11-year-old girl was diagnosed with aHUS following a TMA manifestation with renal impairment, and received plasma and red blood cell infusions and hemodialysis. Following discontinuation of hemodialysis, decreased visual acuity caused by bilateral retinal vein occlusion/venous stasis retinopathy occurred. The ocular involvement resolved after 3 weeks of supportive care, although the patient developed sudden-onset diplopia and bilateral optic disc edema during another TMA manifestation that was treated with systemic steroids.
Infectious diseases often precede onset or a manifestation of aHUS. ${ }^{5}$ Thus, complement dysregulation may have been preceded by $C$. difficile colitis in this patient. In addition to the ocular event, other nonrenal symptoms experienced by this patient may have been part of her TMA manifestations. Extrarenal involvement, including central nervous system, cardiovascular, peripheral vascular and skin, pulmonary, gastrointestinal, skeletal muscle, and connective tissue, is increasingly being identified and characterized in patients with aHUS, and it has been recommended that clinicians increase their alertness to the possibility of TMA manifestations in almost any organ system. ${ }^{23}$ Such extrarenal or multisystemic TMA is thought to occur in up to $48 \%$ of patients, with neurologic and cardiovascular involvement being most common., ${ }^{4-26}$ In this case, the patient presented with gastrointestinal symptoms (ie, abdominal pain, vomiting, and diarrhea $)^{4,25-28}$ and later developed seizures, ${ }^{24,26-28}$ altered mental status, ${ }^{26,28}$ and hypertensive crisis, ${ }^{29-31}$ which have been associated with aHUS. Thus, it is possible that my patient's disease course included more organ systems than the identified renal and ocular manifestations. Effects of eculizumab on extrarenal manifestations of aHUS were not evaluated in the clinical trials. ${ }^{13-16}$ However, case studies have demonstrated the effectiveness of eculizumab for resolution of confirmed or suspected neurologic, ${ }^{28,31-36}$ cardiovascular, ${ }^{29-31,34,35,37}$ peripheral vascular, ${ }^{38}$ pulmonary, ${ }^{30,34,36}$ gastrointestinal, ${ }^{36,39,40}$ and $\operatorname{skin}^{41}$ manifestations of the disease.

\section{Conclusion}

Ocular involvement in aHUS is rare, but ophthalmologic examinations should occur promptly in patients with relevant signs/symptoms. Clinicians also should consider monitoring of ophthalmologic health for all patients with aHUS, particularly those with complement factor $\mathrm{H}$ mutations/ polymorphisms that have been associated with ocular diseases. This case report provides additional evidence for the effectiveness of eculizumab in resolving ocular manifestations in aHUS patients. Ongoing eculizumab therapy has been demonstrated to maintain improvements in hematologic values, renal function, and quality of life in clinical studies in patients with aHUS. ${ }^{14}$ To prevent additional ocular, renal, and extrarenal manifestations of TMA, this patient will be treated with lifelong eculizumab therapy.

\section{Acknowledgment}

The author would like to acknowledge Kristen W Quinn, $\mathrm{PhD}$, of Peloton Advantage, LLC, who provided medical 
writing/editorial support with funding from Alexion Pharmaceuticals, Inc.

\section{Disclosure}

Dr Greenwood has received honoraria from Alexion Pharmaceuticals, Inc. Medical writing/editorial support for this manuscript was funded by Alexion Pharmaceuticals, Inc. The author has no other conflicts of interest in this work.

\section{References}

1. Noris M, Remuzzi G. Atypical hemolytic-uremic syndrome. $N$ Engl $J$ Med. 2009;361(17):1676-1687.

2. Zipfel PF, Heinen S, Skerka C. Thrombotic microangiopathies: new insights and new challenges. Curr Opin Nephrol Hypertens. 2010;19(4):372-378.

3. Benz K, Amann K. Thrombotic microangiopathy: new insights. Curr Opin Nephrol Hypertens. 2010;19(3):242-247.

4. Noris M, Caprioli J, Bresin E, et al. Relative role of genetic complement abnormalities in sporadic and familial aHUS and their impact on clinical phenotype. Clin J Am Soc Nephrol. 2010;5(10): 1844-1859.

5. Campistol JM, Arias M, Ariceta G, et al. An update for atypical haemolytic uraemic syndrome: diagnosis and treatment. A consensus document. [Actualización en síndrome hemolitico urémico atipico: diagnóstico y tratamiento. Documento de consenso] Nefrologia. 2013;33(1):27-45. English and Spanish.

6. Catón B, Díaz de Otazu R, Aldamiz-Echebarria M, Viguri A. Haemolytic-uraemic syndrome with thrombotic microangiopathy of the retina following cytomegalovirus infection: postmortem findings. Postgrad Med J. 1993;69(814):653-655.

7. Benzimra RE, Antao AJ, Donovan KL, Williams AJ. The association between retinal ischaemia and end-stage renal damage in thrombotic microangiopathy. QJM. 1998;91(6):417-422.

8. Larakeb A, Leroy S, Frémeaux-Bacchi V, et al. Ocular involvement in hemolytic uremic syndrome due to factor $\mathrm{H}$ deficiency - are there therapeutic consequences? Pediatr Nephrol. 2007;22(11):1967-1970.

9. David R, Hochberg-Klein S, Amer R. Resolution of ocular involvement with systemic eculizumab therapy in atypical hemolytic-uremic syndrome. Eye (Lond). 2013;27(8):997-998.

10. Zheng X, Gorovoy IR, Mao J, Jin J, Chen X, Cui QN. Recurrent ocular involvement in pediatric atypical hemolytic uremic syndrome. J Pediatr Ophthalmol Strabismus. 2014;51:e62-e65.

11. Alexion Pharmaceuticals, Inc. Soliris ${ }^{\circledR}$ (eculizumab) [prescribing information]. Cheshire, CT: Alexion Pharmaceuticals, Inc.; 2014. Available from: http://www.soliris.net/sites/default/files/assets/ soliris_pi.pdf. Accessed September 8, 2015.

12. Alexion Europe SAS. Soliris (eculizumab) [summary of product characteristics]. European Medicines Agency; 2015. Available from: http://www.ema.europa.eu/docs/en_GB/document_library/ EPAR_-_Summary_for_the_public/human/000791/WC500054210. pdf. Accessed September 8, 2015.

13. Legendre CM, Licht C, Muus $\mathrm{P}$, et al. Terminal complement inhibitor eculizumab in atypical hemolytic-uremic syndrome. $N$ Engl $J$ Med. 2013;368(23):2169-2181.

14. Licht C, Greenbaum LA, Muus P, et al. Efficacy and safety of eculizumab in atypical hemolytic uremic syndrome from 2-year extensions of phase 2 studies. Kidney Int. 2015;87(5):1061-1073.

15. Greenbaum LA, Fila M, Tsimaratos M, et al. Eculizumab (ECU) inhibits thrombotic microangiopathy (TMA) and improves renal function in pediatric atypical hemolytic uremic syndrome (aHUS) patients (Pts). J Am Soc Nephrol. 2013;24:821A-822A.

16. Fakhouri F, Hourmant M, Campistol JM, et al. Eculizumab (ECU) inhibits thrombotic microangiopathy (TMA) and improves renal function in adult atypical hemolytic uremic syndrome (aHUS) patients (Pts). J Am Soc Nephrol. 2013;24:49A-50A.
17. Zuber J, Fakhouri F, Roumenina LT, Loirat C, Frémeaux-Bacchi V; French Study Group for aHUS/C3G. Use of eculizumab for atypical haemolytic uraemic syndrome and $\mathrm{C} 3$ glomerulopathies. Nat Rev Nephrol. 2012;8(11):643-657.

18. Coppo P, Schwarzinger M, Buffet M, et al; French Reference Center for Thrombotic Microangiopathies. Predictive features of severe acquired ADAMTS13 deficiency in idiopathic thrombotic microangiopathies: the French TMA Reference Center experience. PLoS One. 2010;5(4):e10208.

19. Cataland SR, Wu HM. How I treat: the clinical differentiation and initial treatment of adult patients with atypical hemolytic uremic syndrome. Blood. 2014;123(16):2478-2484.

20. Hageman GS, Anderson DH, Johnson LV, et al. A common haplotype in the complement regulatory gene factor $\mathrm{H}(\mathrm{HF} 1 / \mathrm{CFH})$ predisposes individuals to age-related macular degeneration. Proc Natl Acad Sci U S A. 2005;102(20):7227-7232.

21. Thakkinstian A, Han P, McEvoy M, et al. Systematic review and meta-analysis of the association between complement factor $\mathrm{HY} 402 \mathrm{H}$ polymorphisms and age-related macular degeneration. Hum Mol Genet. 2006;15(18):2784-2790.

22. Herbert AP, Deakin JA, Schmidt CQ, et al. Structure shows that a glycosaminoglycan and protein recognition site in factor $\mathrm{H}$ is perturbed by age-related macular degeneration-linked single nucleotide polymorphism. J Biol Chem. 2007;282(26):18960-18968.

23. Hofer J, Rosales A, Fischer C, Giner T. Extra-renal manifestations of complement-mediated thrombotic microangiopathies. Front Pediatr. 2014;2:97.

24. Neuhaus TJ, Calonder S, Leumann EP. Heterogeneity of atypical haemolytic uraemic syndromes. Arch Dis Child. 1997;76(6):518-521.

25. Sellier-Leclerc AL, Fremeaux-Bacchi V, Dragon-Durey MA, et al; French Society of Pediatric Nephrology. Differential impact of complement mutations on clinical characteristics in atypical hemolytic uremic syndrome. J Am Soc Nephrol. 2007;18(8):2392-2400.

26. Geerdink LM, Westra D, van Wijk JA, et al. Atypical hemolytic uremic syndrome in children: complement mutations and clinical characteristics. Pediatr Nephrol. 2012;27(8):1283-1291.

27. Dragon-Durey MA, Sethi SK, Bagga A, et al. Clinical features of antifactor $\mathrm{H}$ autoantibody-associated hemolytic uremic syndrome. $J \mathrm{Am}$ Soc Nephrol. 2010;21(12):2180-2187.

28. Ohanian M, Cable C, Halka K. Eculizumab safely reverses neurologic impairment and eliminates need for dialysis in severe atypical hemolytic uremic syndrome. Clin Pharmacol. 2011;3:5-12.

29. Bekassy ZD, Kristoffersson AC, Cronqvist M, et al. Eculizumab in an anephric patient with atypical haemolytic uraemic syndrome and advanced vascular lesions. Nephrol Dial Transplant. 2013;28(11):2899-2907.

30. Román-Ortiz E, Mendizabal Oteiza S, Pinto S, López-Trascasa M, Sánchez-Corral P, Rodríguez de Cordoba S. Eculizumab long-term therapy for pediatric renal transplant in aHUS with CFH/CFHR1 hybrid gene. Pediatr Nephrol. 2014;29(1):149-153.

31. Ávila A, Vizcaíno B, Molina P, Gavela E, Perez-Ebri M, Pallardó L. Remission of aHUS neurological damage with eculizumab. Clin Kidney J. 2015;8(2):232-236.

32. Gulleroglu K, Fidan K, Hançer VS, Bayrakci U, Baskin E, Soylemezoglu O. Neurologic involvement in atypical hemolytic uremic syndrome and successful treatment with eculizumab. Pediatr Nephrol. 2013;28(5):827-830.

33. Povey H, Vundru R, Junglee N, Jibani M. Renal recovery with eculizumab in atypical hemolytic uremic syndrome following prolonged dialysis. Clin Nephrol. 2014;82(5):326-331.

34. Diamante Chiodini B, Davin JC, Corazza F, et al. Eculizumab in antifactor $\mathrm{h}$ antibodies associated with atypical hemolytic uremic syndrome. Pediatrics. 2014;133(6):e1764-e1768.

35. Hu H, Nagra A, Haq MR, Gilbert RD. Eculizumab in atypical haemolytic uraemic syndrome with severe cardiac and neurological involvement. Pediatr Nephrol. 2014;29(6):1103-1106.

36. Tsai HM, Kuo E. Eculizumab therapy leads to rapid resolution of thrombocytopenia in atypical hemolytic uremic syndrome. Adv Hematol. 2014;2014:295323. 
37. Vilalta R, Lara E, Madrid A, et al. Long-term eculizumab improves clinical outcomes in atypical hemolytic uremic syndrome. Pediatr Nephrol. 2012;27(12):2323-2326.

38. Malina M, Gulati A, Bagga A, Majid MA, Simkova E, Schaefer F. Peripheral gangrene in children with atypical hemolytic uremic syndrome. Pediatrics. 2013;131(1):e331-e335.

39. Green H, Harari E, Davidovits M, et al. Atypical HUS due to factor $\mathrm{H}$ antibodies in an adult patient successfully treated with eculizumab. Ren Fail. 2014;36(7):1119-1121.
40. Webb TH, Griffiths H, Miyashita Y, et al. Atypical hemolytic uremic syndrome and chronic ulcerative colitis treated with eculizumab. Int $J$ Med Pharm Case Reports. 2015;4(5):105-112.

41. Ardissino G, Tel F, Testa S, et al. Skin involvement in atypical hemolytic uremic syndrome. Am J Kidney Dis. 2014;63(4):652-655.

International Medical Case Reports Journal

\section{Publish your work in this journal}

The International Medical Case Reports Journal is an international, peer-reviewed open-access journal publishing original case reports from all medical specialties. Previously unpublished medical posters are also accepted relating to any area of clinical or preclinical science. Submissions should not normally exceed 2,000 words or
4 published pages including figures, diagrams and references. The manuscript management system is completely online and includes a very quick and fair peer-review system, which is all easy to use. Visit http://www.dovepress.com/testimonials.php to read real quotes from published authors.

Submit your manuscript here: http://www.dovepress.com/international-medical-case-reports-journal-journal 